\title{
Comparación de métodos de inoculación de Fusarium oxysporum f. sp. lycopersici (Sacc.) Snyder \& Hansen, causante del marchitamiento vascular del tomate
}

\author{
(D) Luisa Fernanda Cardona-Piedrahíta ${ }^{1, *}$, (D) Jairo Castaño-Zapata ${ }^{2}$ \\ ${ }^{1}$ Corporación Universitaria Santa Rosa de Cabal, UNISARC, Santa Rosa de Cabal, Risaralda, Colombia \\ ${ }^{2}$ Facultad de Ciencias Agropecuarias, Universidad de Caldas, Manizales, Colombia
}

\begin{abstract}
Resumen
El tomate (Solanum lycopersicum L.), la hortaliza de mayor importancia en Colombia y en el mundo, es atacada por numerosas enfermedades, entre ellas la marchitez vascular causada por Fusarium oxysporum f. sp. lycopersici. La enfermedad produce pérdidas entre el 21 y el $47 \%$ en cultivos en exposición libre y bajo cubierta. El objetivo del presente trabajo fue comparar cuatro métodos de inoculación del hongo en plántulas de tomate Sweet Million obtenidas a partir de semilla, sembradas en turba canadiense estéril y medio Murashige \& Skoog (MS) y conservadas en condiciones controladas en el Laboratorio de Tejidos Vasculares y del cuarto de termoterapia de la Universidad de Caldas donde se seleccionaron 25 plántulas por cada método de inoculación. Los tratamientos fueron: inyección en la corona de la raíz $\left(\mathrm{T}_{1}\right)$, inmersión de las raíces $\left(\mathrm{T}_{2}\right)$, disco de agar en la corona de la raíz $\left(\mathrm{T}_{3}\right)$ e inoculación in vitro $\left(\mathrm{T}_{4}\right)$. En la incidencia final de la enfermedad, así como las pruebas comparativas de Duncan, se registraron diferencias significativas $(\mathrm{p} \leq 0,001)$ entre los diferentes métodos de inoculación. La única metodología que produjo el $100 \%$ de incidencia del marchitamiento vascular en un menor periodo de incubación fue la inoculación in vitro. La mayor tasa de desarrollo (r) del marchitamiento vascular se reportó con el método de inoculación in vitro con una tasa de $\mathrm{r}=0,92$, seguido por los discos de agar, la inmersión y la inyección, siendo estas dos últimas las de menor tasa de desarrollo. El método de inoculación in vitro puede ser útil para la selección masiva de materiales de tomate promisorios contra la marchitez vascular. C 2019. Acad. Colomb. Cienc. Ex. Fis. Nat.
\end{abstract}

Palabras clave: Fusarium; Forma especial; Nectriaceae; Hortaliza; Solanaceae; in vitro.

Comparison of inoculation methods of Fusarium oxysporum f. sp. lycopersici Sacc. (Snyder \& Hansen), the causal agent of the vascular wilt of tomato

\begin{abstract}
Tomato (Solanum Lycopersicum L.), the most important vegetable in Colombia and worldwide, is attacked by numerous diseases, among them, the vascular wilting caused by Fusarium oxysporum $\mathrm{f}$. sp. lycopersici. The disease can cause losses between 21 and $47 \%$ in full exposure and under cover crops. The objective of this work was to compare four inoculation methods of this fungus in seedlings of the Sweet Million cultivar obtained from seeds and planted in sterilized Canadian peat and in MS medium and maintained under controlled conditions at the Laboratory of Tissue Culture and thermotherapy room of the Universidad de Caldas where 25 seedlings were selected per method of inoculation. The treatments were: Injection in the crown root $\left(\mathrm{T}_{1}\right)$, immersion of the roots $\left(\mathrm{T}_{2}\right)$, agar disc in the crown root $\left(\mathrm{T}_{3}\right)$, and inoculation in vitro $\left(\mathrm{T}_{4}\right)$. The final disease incidence and the comparative tests of Duncan showed highly significant differences $(\mathrm{p} \leq 0.001)$ among the different methods of inoculation. The only method that induced a $100 \%$ incidence of the vascular wilt in the shortest period of incubation was the in vitro method. The highest rate of disease development ( $\mathrm{r}$ ) was obtained with the in vitro inoculation method $(\mathrm{r}=0.92)$ followed by agar discs, immersion, and injection. The in vitro inoculation method can be useful for the massive selection of tomato materials promising against vascular wilt. (C) 2019. Acad. Colomb. Cienc. Ex. Fis. Nat.
\end{abstract}

Key words: Fusarium; Formae special; Nectriaceae; Vegetable; Solanaceae; in vitro.

\footnotetext{
*Correspondencia:

Luisa Fernanda Cardona-Piedrahíta; luisa.cardona@unisarc.edu.co; Recibido: 11 de marzo de 2019; Aceptado: 26 de abril de 2019

Editor: Elizabeth Castañeda
} 


\section{Introducción}

El tomate (Solanum lycopersicum L.) es una de las hortalizas más consumidas en el mundo; su producción en el 2017 fue de 241.641.489 t (FAOSTAT, 2017). Se cultiva en más de 100 países para consumo fresco e industrial; el $81 \%$ de la producción se concentra en China, India, Estados Unidos, Turquía, Egipto, Irán, Italia, España, México y Brasil (FAOSTAT, 2017). El consumo promedio en países desarrollados es de $86 \mathrm{~g}$ diarios per cápita y en países en vía de desarrollo, 27 g. Colombia produjo 714.314 t en el 2017, con un rendimiento promedio de $33,94 \mathrm{t} / \mathrm{ha}$. El rendimiento promedio mundial es de 55,27 t/ha, cifra por debajo de la obtenida en áreas con mayor rendimiento y gran tecnificación como Bélgica (496 t/ha), Reino Unido (388,95 t/ha) y Noruega (320,39t/ha) (FAOSTAT, 2017).

El tomate tiene su origen en la región andina que se extiende desde el sur de Colombia al norte de Chile (Rick, 1974), lo que explica la cantidad de patógenos que limitan su producción; además, del incremento del área sembrada y la popularización del monocultivo, en Colombia se reportan 48 enfermedades importantes, entre las cuales se encuentra la marchitez vascular, la cual es causada por el hongo Fusarium oxysporum f. sp. lycopersici (Sacc.) Snyder \& Hansen, una de las más de 100 formas especiales que se conocen de Fusarium oxysporum, de amplia distribución mundial (Gordon, 2017). Este hongo pertenece al reino Fungi, división Ascomycota, subdivisión Pezizomycotina, clase Sordariomycetes, subclase Hypocreomycetidae, orden Hypocreales, familia Nectriaceae, género Fusarium (Mycobank, 2017).

La enfermedad causa pérdidas entre el 21 y el $47 \%$ en cultivos en exposición libre y bajo cubierta (Ramyabharathi, et al., 2012; Singh \& Dwivedi, 2014). En Colombia aún no se conocen datos sobre pérdidas por esta enfermedad. Cuando este patógeno ataca plántulas ocasiona el mal del talluelo, el cual es favorecido por la carencia de lignina en el tallo, lo que las hace más susceptibles y permite que el patógeno alcance rápidamente los vasos del xilema, causando la destrucción y el colapso del tejido (Agrios, 2005). Los síntomas tempranos que presentan las plántulas de tomate incluyen coloración amarillenta, pérdida prematura de cotiledones y hojas inferiores, y retraso del crecimiento, se observa, además, una lesión marrón pronunciada que rodea el hipocótilo (unión entre raíz y brote) (McGovern \& Datnoff, 1992). El tejido vascular de una planta enferma se torna de color pardo oscuro, siendo más notable en el punto de unión del peciolo con el tallo; este color es característico de la enfermedad y se emplea para su identificación (Jones, 1991). El marchitamiento de las hojas, la pudrición de la raíz $\mathrm{y}$, finalmente, la muerte, son señal de la enfermedad en su estado más avanzado (McGovern \& Datnoff, 1992).

El hongo produce las siguientes tres clases de esporas asexuales.

Microconidios. Conformados por una o dos células, son los más frecuentes y los únicos que se pueden producir en el interior de los haces vasculares de las plantas afectadas sin septos. Son hialinos, elipsoidales a cilíndricos, rectos o curvados; se forman sobre fiálides laterales, cortas y simples, o sobre conidióforos poco ramificados. Los microconidios miden entre 5 y $12 \mu \mathrm{m}$ de largo por 2,5 a 3,5 $\mu \mathrm{m}$ de ancho (Figura 1A) (Nelson, 1981; Leslie \& Summerell, 2006). Los que son mucho más pequeños pueden formarse tanto en la superficie como en el interior del hospedante e, incluso, pueden ser transportados por la savia hacia los haces vasculares. La diseminación de la enfermedad en las plantas vecinas es posible por contacto directo de una planta infectada y una sana, así como también a través de las raíces. También es posible la transmisión de la enfermedad por la semilla (Kranz, 1982).

Macroconidios. Estos se forman en esporodoquios de color naranja pálido, generalmente abundantes cuando se siembran en agar de papa y dextrosa (PDA) complementado con hojas de clavel, y son curvos, con tres a cinco células. Se ha observado que la mayoría de los macroconidios de los aislamientos de esta especie presentan diversos tamaños que varían entre 20,3 y 27,0 $\mu \mathrm{m}$ de largo y $6,7 \mu \mathrm{m}$ de ancho (Figura 1B) (Leslie \& Summerell, 2006; Lugo \& Sanabria, 2001). Los macroconidios del hongo producidos sobre los tejidos del hospedante pueden ser transportados por el viento, las gotas de lluvia, la maquinaria agrícola o
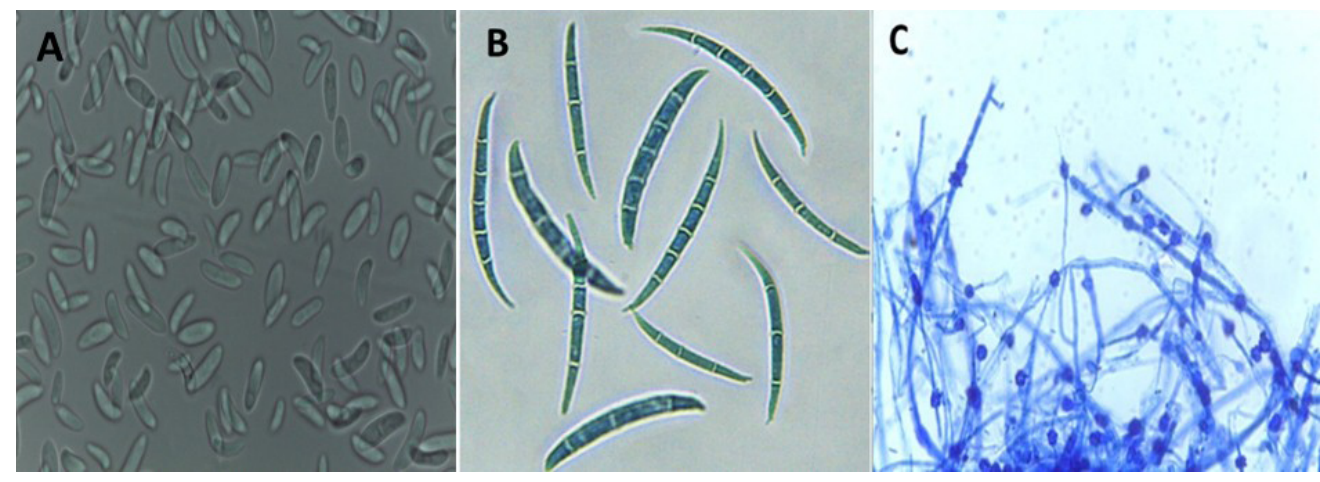

Figura 1. A. Microconidios de Fusarium oxysporum f. sp. lycopersici (100X). B.- Macroconidios (40X). C. Clamidosporas de Fusarium oxysporum f. sp. Lycopersici. $40 \mathrm{X}$ 
por los humanos, entre otros. Las infecciones secundarias suelen producirse a través de las raíces, aunque también son posibles a través de heridas en la parte aérea de las plantas (Kranz, 1982).

Clamidosporas. En el medio PDA complementado con hojas de clavel se forman muy rápido, en un periodo de 2 a 4 semanas, a partir de la condensación del contenido de las hifas y de los conidios, cuyas paredes son gruesas. Se forman simples o en pares, terminales o intercalares y miden de 5 a $15 \mu \mathrm{m}$ de diámetro (Figura 1C) (Leslie \& Summerell, 2006; Nelson, 1981). Son estructuras de supervivencia que pueden perdurar en el suelo y germinan y se introducen a través de las heridas que se forman cuando las raíces laterales emergen, o penetran directamente al tejido joven de las raíces en la zona de elongación. El micelio avanza intercelularmente y alcanza la región del xilema. El hongo se desarrolla en las traqueidas y en los vasos y células parenquimatosas. El micelio se ramifica y produce microconidios, los cuales se desprenden y son arrastrados hacia arriba por el flujo de la savia, vuelven a germinar y producen más micelio y microconidios (Agrios, 2005).

El patógeno puede permanecer en el suelo en forma de clamidosporas durante seis o más años como saprófito, sin un hospedante (Cerkauskas, 2005).

Generalmente, el hongo penetra en las plantas de tomate por las raíces, causando una obstrucción de los tejidos vasculares y pardeamiento. Los primeros síntomas de la enfermedad son el amarillamiento del follaje, seguido por defoliación. Las hojas infectadas posteriormente se oscurecen y se secan. La parte superior de la planta se marchita durante el día y se recupera en la noche, pero el marchitamiento se incrementa hasta que la planta se marchita completamente y se observa el oscurecimiento vascular en los tallos y los pecíolos de las hojas maduras infectados. Las plantas afectadas y sus sistemas radicales se atrofian. Bajo condiciones de mucha humedad, en los tejidos atacados y con pudrición seca se forma un micelio aéreo blanco cubierto por macroconidios que puede tornarse de color rosa anaranjado; esto ocurre con frecuencia cerca de la superficie del suelo o en cultivos con gran densidad de siembra (Kranz, 1982).

El hongo produce retraso en el crecimiento y síntomas de marchitamiento foliar, hasta que ocurre la quemazón foliar y el secamiento total de las plantas de tomate, y se produce una necrosis interna de color marrón en la base del tallo (Jaramillo, et al., 2007).

Por la gravedad de los síntomas, la resistencia genética es el método más eficiente, económico y ecológico de manejo del marchitamiento vascular en el tomate. Sin embargo, para el proceso de evaluación y de selección de genotipos resistentes, es necesario inducir el desarrollo de los síntomas de la enfermedad mediante un método de inoculación eficiente que permita clasificar la reacción de los diferentes genotipos evaluados. Los métodos de inoculación artificial permiten observar la variabilidad en los periodos de incubación y de latencia del hongo, el proceso de colonización, el mecanismo de patogenia, la edad óptima de sensibilidad al agente causante de la enfermedad, así como la optimización del tiempo y los recursos económicos (Castaño-Zapata, 1994; Ortiz \& Hoyos, 2016).

Para la selección de materiales de tomate y otros cultivos resistentes a Fusarium spp., se han descrito diferentes métodos de inoculación (Lozovaya, et al., 2004; Fischer, et al., 2005; Narayanasamy, 2011; Ortiz \& Hoyos, 2016; Ángel-García, et al., 2018), pero en Colombia el desarrollo de métodos de inoculación de $F$. oxysporum $\mathrm{f}$. sp. lycopersici en tomate aún no se ha estudiado. Por esta razón, la presente investigación tuvo como objetivo evaluar la eficiencia de cuatro métodos de inoculación para inducir los síntomas causados por $F$. oxysporum f. sp. lycopersici en plántulas de tomate bajo condiciones controladas de luz y de temperatura.

\section{Materiales y métodos}

Recolección de material vegetal. El material vegetal con sintomatología típica del marchitamiento vascular se obtuvo de una finca comercial ubicada en la vereda Alto Bonito del municipio de Neira (Caldas) a una altura de 1.969 m.s.n.m., y una temperatura promedio anual de $19{ }^{\circ} \mathrm{C}$. Se recolectaron muestras de raíces y tallos de plantas de tomate en estado vegetativo, las cuales se guardaron en bolsas de plástico debidamente selladas y rotuladas que posteriormente se llevaron al Laboratorio de Fitopatología de la Universidad de Caldas.

Aislamiento y prueba de patogenia del hongo. Se procedió a hacer la siembra de tejido en medio de cultivo PDA (39 g/L de agua). Se hicieron cortes longitudinales en la corona de las raíces de las plantas que presentaban síntomas de necrosis en el área de los haces vasculares; en la cámara de flujo laminar se tomaron porciones de tejido de aproximadamente $3 \mathrm{~mm}$ de diámetro y se desinfectaron con una solución de hipoclorito de sodio al $1 \%$, luego se pasaron a una solución de alcohol antiséptico al $70 \%$ y, por último, se lavaron en agua destilada estéril dejando el tejido sumergido en cada una de las soluciones durante un minuto. Se sembraron cuatro porciones de tejido en cada una de las cajas de Petri $(9 \mathrm{~cm} \times 1,5 \mathrm{~cm})$ que contenían $20 \mathrm{~mL}$ de PDA, y estas se rotularon con el número de la muestra, la repetición y la fecha de siembra, y posteriormente se sellaron con papel vinilpel (marca Cristaflex) y se llevaron a una incubadora digital marca WTB Binder calibrada a $27^{\circ} \mathrm{C}$ en condiciones de oscuridad hasta observar esporulación abundante del hongo. Siguiendo la metodología de Castaño-Zapata \& Salazar (1998), se extrajeron las estructuras reproductivas del hongo de 15 días de edad con una aguja de disección y se colocaron en una lámina portaobjetos con dos gotas de azul de lactofenol al 0,05\% (20 g de fenol cristalino $+20 \mathrm{~cm}^{3} \mathrm{de}$ ácido láctico $+20 \mathrm{~cm}^{3}$ de glicerina $+20 \mathrm{~cm}^{3}$ de agua destilada y azul de algodón al $5 \%$ en agua); la muestra se cubrió con un cubreobjetos y se procedió a observarla bajo un microscopio 
compuesto de luz Scientific Revelation III (LW Scientific) con objetivo de 40X, para observar las características morfológicas de Fusarium oxysporum f. sp. lycopersici descritas por Leslie \& Summerell (2006).

Purificación del hongo. Después de observar los macroconidios septados y los microconidios (en su mayoría unicelulares) característicos del patógeno, se tomó un trozo del crecimiento micelial del primer aislamiento (incluida una pequeña porción de la colonia), con un poco de medio de cultivo utilizando una aguja de disección, el cual se colocó con PDA en cajas de Petri debidamente rotuladas que se llevaron a una incubadora a $27^{\circ} \mathrm{C}$ en oscuridad; diariamente se observó el micelio, así como la formación de las estructuras reproductivas del hongo.

Métodos de inoculación. Se establecieron cuatro métodos de inoculación: 1) método de inyección en la corona de la raíz; 2) método por inmersión de las raíces; 3) método de discos de agar en la corona de la raíz, y 4) método de inoculación en plántulas in vitro. Estas metodologías se aplicaron en plántulas de tomate Sweet Million (Solanum lycopersicum L.) obtenidas a partir de semillas sembradas en turba canadiense estéril y medio MS (4,6 g/L de agua + $30 \mathrm{~g} / \mathrm{L}$ de sacarosa $+7,5 \mathrm{~g} / \mathrm{L}$ de Phytagel ${ }^{\circledR}$ ) (Murashige \& Skoog, 1962) conservadas en condiciones controladas del Laboratorio de Tejidos Vegetales y del cuarto de termoterapia de la Universidad de Caldas donde se seleccionaron 25 plántulas en buenas condiciones de desarrollo por método.

Inyección en la corona de la raiz $\left(T_{1}\right)$. En el laboratorio se hizo la inoculación inyectando el hongo de 15 días de edad purificado en agar PDA a 25 plántulas de tomate Sweet Million cuando éstas tenían tres hojas verdaderas (código $\mathrm{BBCH} 103$ ); en cada plántula se inyectó en la corona de la raíz $1 \mathrm{~mL}$ de suspensión conidial con una concentración de $1 \times 10^{6}$ conidios por $\mathrm{mL}^{-1}$ de agua destilada estéril con jeringas para insulina de $1 \mathrm{~mL}$ (Okiror, 1998). Posteriormente, se trasplantaron en bolsas de plástico con dimensiones de 25 $\mathrm{cm}$ de alto x $10 \mathrm{~cm}$ de diámetro llenadas con turba Spagnum estéril y se dejaron en condiciones de laboratorio a una temperatura promedio de $18,5^{\circ} \mathrm{C}$.

Inmersión de las raíces $\left(T_{2}\right)$. Esta inoculación se hizo siguiendo la metodología propuesta por Williams (1981) y Estupiñan \& Ossa (2007). Se retiraron cuidadosamente de las bandejas de germinación 25 plántulas de tomate cultivar Sweet Million de 30 días de edad obtenidas a partir de semilla; se hizo un lavado de las raíces con agua de grifo y con unas tijeras estériles se cortaron los ápices de la raíz principal. Posteriormente, cada una de las plántulas se sumergió hasta el cuello de la raíz durante 30 minutos en vasos de precipitación que contenían $250 \mathrm{~mL}$ de la suspensión conidial concentrada de $1 \times 10^{6}$ conidios por $\mathrm{mL}^{-1} \mathrm{de}$ agua destilada estéril. Finalizado este proceso, las plántulas se sembraron en bolsas de plástico con turba Spagnum esteril $\mathrm{y}$ se dejaron en condiciones de laboratorio a una temperatura promedio de $18,5^{\circ} \mathrm{C}$ con fotoperiodo de 12 horas de día y 12 horas de noche.
Disco de agar en la corona de la raiz $\left(T_{3}\right)$. Se trasplantaron 25 plántulas de tomate Sweet Million de 30 días de edad obtenidas a partir de semilla provenientes de bandejas de germinación con suelo esteril a vasos que contenían turba Spagnum esteril. Después se cortaron con la boca de un tubo de ensayo estéril porciones de agar PDA de $1 \mathrm{~cm}$ de diámetro con un crecimiento del patógeno de 15 días, y el disco de agar se colocó con las esporas del hongo en la base del tallo de cada plántula para después ser llevadas al cuarto de termoterapia bajo condiciones controladas.

Inoculación in vitro $\left(T_{4}\right)$. Se realizaron pruebas de patogenia en 25 plántulas de tomate Sweet Million de una edad de 30 días obtenidas a partir de semilla; cada semilla se sembró en $25 \mathrm{~mL}$ de medio nutritivo MS vertido en frascos de vidrio de $4 \mathrm{~cm}$ de diámetro $\mathrm{x} 7 \mathrm{~cm}$ de alto, los cuales fueron cuidadosamente tapados y sellados con papel vinilpel (Cristaflex). Las plántulas crecieron bajo condiciones controladas en el Laboratorio de Tejidos Vegetales a una temperatura promedio de $18,5^{\circ} \mathrm{C}$ y una intensidad lumínica de 16 horas de luz y 8 horas de oscuridad. La inoculación individual de cada plántula se efectuó con $1 \mathrm{~mL}$ de suspensión conidial en una concentración de $1 \times 10^{6}$ conidios por $\mathrm{mL}^{-1}$ de agua destilada estéril, la cual se depositó en la base del tallo mediante una micropipeta de 10-1.000 $\mu \mathrm{L}$ (Himedia ${ }^{\circledR}$ ).

La concentración de la suspensión conidial utilizada se ajustó con la ayuda de un hemacitómetro (Bright Line ${ }^{\circledR}$ ) siguiendo la metodología descrita por Castaño-Zapata (1998): se contaron los macroconidios y microconidios en la cuadrícula del centro y de las cuatro esquinas del hemacitómetro, cada una con un área de $1 \mathrm{~mm}^{2}$, se sumó el número de conidios de las cinco cuadrículas y el resultado se multiplicó por 50.000, que es una constante, y se hicieron mediciones y diluciones hasta obtener la concentración deseada de $1 \times 10^{6}$ conidios por $\mathrm{mL}^{-1}$ de agua.

Variables evaluadas. Se determinó la incidencia de la enfermedad aplicando la siguiente fórmula:

Incidencia (\%) = Número de individuos enfermos/ total de individuos $* 100$.

También se determinó el periodo de incubación, definido como el tiempo necesario para que se desarrollaran los signos de la enfermedad desde el momento de la inoculación hasta su expresión. Asimismo, se calculó la tasa de desarrollo de la enfermedad. Al ser Fusarium oxysporum f. sp. lycopersici un patógeno monocíclico, no se debería tener en cuenta el factor de corrección $\log _{\mathrm{e}}(1 / 1-\mathrm{X})$, sin embargo, la incidencia superó el $\mathrm{X}=0,05$, por lo que se empleó la formula descrita por Castaño-Zapata (2002):

$$
r=\frac{1}{T_{1}-T_{0}}\left(\log _{e} \frac{X_{1}}{1-X_{1}}-\log _{e} \frac{X_{0}}{1-X_{0}}\right),
$$

donde $\mathrm{r}=$ tasa de desarrollo, $\mathrm{T}_{1}=$ tiempo final, $\mathrm{T}_{0}=$ tiempo inicial, $\mathrm{X}_{1}=$ proporción de incidencia de la enfermedad en tiempo final, $\mathrm{X}_{0}=$ proporción de incidencia de la enfermedad en tiempo inicial.

Análisis de datos. Se utilizó un diseño experimental completamente al azar con cinco tratamientos; la unidad 
experimental fue de cinco plántulas por repetición. Se analizó la varianza y se hicieron pruebas de promedio de tipo Duncan utilizando el programa PROC GLM de SAS (SAS, 1992).

\section{Resultados y discusión}

Incidencia del marchitamiento vascular con los diferentes métodos de inoculación. La incidencia final de la enfermedad mostró diferencias estadísticas muy significativas $(\mathrm{p} \leq 0,001)$ entre los diferentes métodos de inoculación evaluados, así como en las pruebas comparativas de tipo Duncan. La única metodología que produjo el $100 \%$ de incidencia del marchitamiento vascular fue la inoculación in vitro (Figura 2).

Las evaluaciones de incidencia de la enfermedad en cada uno de los métodos de inoculación se realizaron durante 29 días. Con el método in vitro, Fusarium oxysporum f. sp. lycopersici tuvo un periodo de incubación de cinco días y se evidenció el marchitamiento de las plántulas (Figura $3 \mathrm{~A}$ ); al término de los cinco días ya se manifestaba una incidencia del $25 \%$ y para el día 11 se registró una del

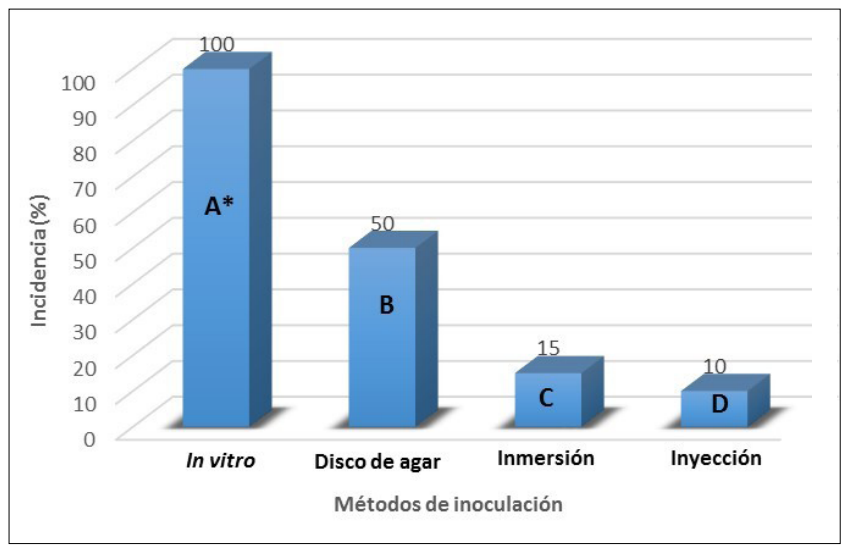

Figura 2. Incidencia final del marchitamiento vascular con cada método de inoculación utilizado

* Las letras diferentes denotan diferencias significativas entre los métodos de inoculación según la prueba de rangos múltiples de Duncan al $5 \%$.
$100 \%$, a lo que siguió la necrosis de las raíces (Figura 3B), el estrangulamiento del cuello del tallo (Figura 3C) y, finalmente, la muerte de las plántulas (Figura 3D), siendo éste el único método de inoculación con el que se registró en un $100 \%$ de las plántulas la patogenia de Fusarium oxysporum f. sp. lycopersici, resultado muy similar al obtenido por Ángel-García, et al. (2018), quienes, al evaluar diferentes métodos de inoculación de Fusarium solani f. sp. passiflorae en plántulas de maracuyá (Passiflora edulis Sims), obtuvieron un $100 \%$ de incidencia de la secadera del maracuyá a los 6,2 días de la inoculación con el método de cribado en tubos de ensayo (Kelman, 1967).

Con el método del disco de agar también se evidenció una respuesta positiva pero no tan completa como con el método anterior. El periodo de incubación del hongo fue de siete días y la incidencia, del $20 \%$; para el día 29 ésta llegó al $50 \%$, aunque no se observó la muerte de las plántulas. Con estos dos métodos se obtuvieron los mejores resultados, lo que podría explicarse por las condiciones ambientales del cuarto de termoterapia a donde se llevaron las plántulas después de las inoculaciones y se mantuvieron con un fotoperiodo de 16 horas de luz y 8 de oscuridad y una temperatura promedio de $20^{\circ} \mathrm{C}$; la temperatura óptima para el crecimiento micelial del hongo oscila entre 27 y $28{ }^{\circ} \mathrm{C}$ (Walker, 1971).

Los métodos que no mostraron un resultado satisfactorio fueron los de inmersión e inyección, ya que el periodo de incubación del hongo fue de 17 días, con una incidencia del 15 y el $10 \%$, respectivamente. Con ambos métodos se observaron síntomas leves de marchitamiento, la incidencia fue baja hasta el final del experimento y no se causó la muerte de las plántulas. Este resultado se considera atípico debido a la agresividad del hongo, pero es posible que haya habido una pérdida de la virulencia del patógeno por el manejo del hongo en el laboratorio, sumado a las pocas condiciones ambientales favorables para su cultivo, ya que una vez se hicieron las inoculaciones, las plántulas se colocaron en la cámara húmeda y se mantuvieron en condiciones de laboratorio a una temperatura promedio de $18,5^{\circ} \mathrm{C}$. Walker (1971) afirma que a temperaturas inferiores a $16{ }^{\circ} \mathrm{C}$ y sobre los $34^{\circ} \mathrm{C}$ los síntomas de la enfermedad dificilmente se desarrollan.
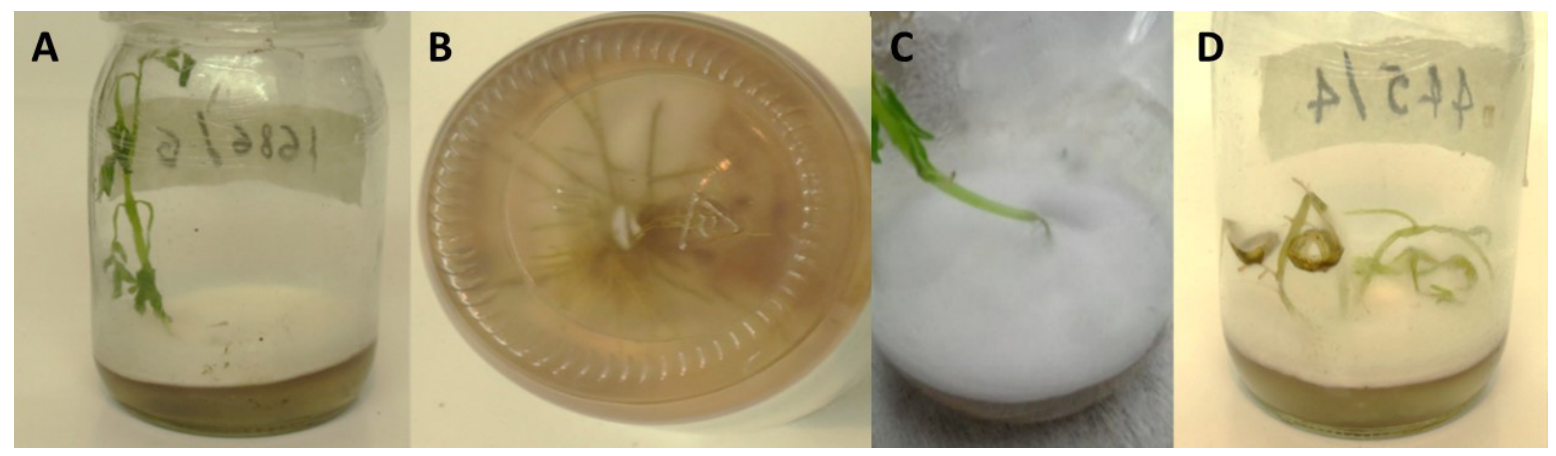

Figura 3. Síntomas observados en el desarrollo del marchitamiento vascular del tomate. A) Marchitamiento de la plántula. B) Necrosis de las raíces. C) Estrangulamiento en el cuello del tallo. D) Muerte de la plántula 


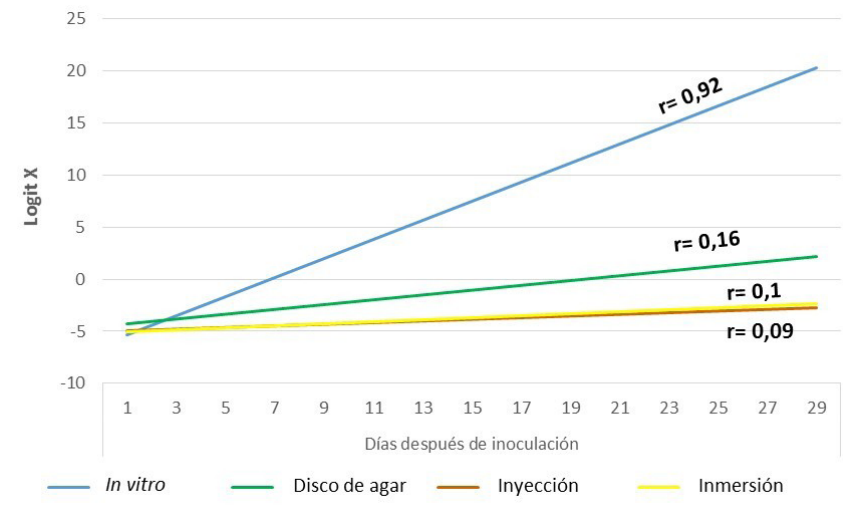

Figura 4. Tasas de desarrollo (r) del marchitamiento vascular causado por Fusarium oxysporum f. sp. lycopersici a lo largo del tiempo con los diferentes métodos de inoculación

Así mismo, en un estudio realizado por Morales, et al. (2014), quienes inocularon Fusarium oxysporum en especies silvestres del género Solanum sección lycopersicon mediante el método de inyección, se registró un periodo de incubación de 15 días y se evidenciaron pocos signos de la enfermedad y, hacia el final del experimento, en el día 32 de la inoculación, no había muerte de plántulas, por lo que los autores concluyeron que la poca virulencia del hongo se debía al proceso de manejo y a la falta de condiciones climáticas para su desarrollo, ya que las plántulas se mantuvieron en baldes plásticos en exposición libre. Sin embargo, utilizando la inoculación por inmersión estos mismos autores no emplearon el hongo aislado, sino el macerado de raíces de plantas con síntomas de la enfermedad provenientes de campos infestados, con lo cual indujeron la muerte del 57,8 \% de las plantas en un periodo de incubación del hongo de 10 días.

En condiciones de laboratorio, López-Cardona \& Castaño-Zapata (2013) inocularon la bacteria Pseudomonas sp. mediante el método de inyección en tallos de tomate de árbol (Solanum betaceum) y obtuvieron un $100 \%$ de incidencia de la muerte descendente y un periodo de incubación de la bacteria de cinco días. Con este método de inoculación se hunde la aguja en el tallo principal para llegar a los vasos conductores de xilema y floema (Jiménez, et al., 2004; Trandafirescu \& Botu, 2009).

Poulsen, et al. (2013) realizaron un estudio de comparación entre técnicas de inoculación de Fusarium verticillioides en espigas de maíz y obtuvieron una mejor respuesta con el método de inyección en el canal de los estigmas, con un promedio de incidencia final de $51 \%$ en los híbridos de maíz evaluados.

Tasas de desarrollo (r) del marchitamiento vascular con los diferentes métodos de inoculación. El cálculo de las tasas de desarrollo del marchitamiento vascular con los diferentes métodos de inoculación evidenció (como era de esperarse después de los resultados de la incidencia de la enfermedad) que la mayor tasa de desarrollo del marchitamiento vascular se logró con el método de inoculación in vitro, seguido por los discos de agar, la inmersión y la inyección, siendo estos dos últimos métodos los que registraron la menor tasa de desarrollo. Asimismo, los resultados permitieron inferir que la tasa de desarrollo tuvo una relación directamente proporcional con la incidencia (Figura 4). En este sentido, Castaño-Zapata (2002) menciona que cuanto mayor es la incidencia de una enfermedad, mayor es su velocidad de desarrollo. En las condiciones del ensayo en el presente estudio, con el método de inoculación in vitro se comprobó la teoría que define el triángulo de la enfermedad, es decir, un hospedante genéticamente susceptible, un patógeno genéticamente virulento y un medio ambiente favorable. Ninguno de estos componentes es independiente.

En conclusión, aunque los métodos de inoculación empleados en este estudio indujeron los síntomas de la enfermedad, el método de inoculación in vitro fue el más eficiente debido a la homogeneidad en los resultados obtenidos para las variables evaluadas de incidencia, tasa de desarrollo y periodo de incubación en condiciones controladas. Dicho método puede ser útil para la selección masiva de materiales promisorios de tomate por su reacción a la marchitez vascular.

\section{Contribución de los autores}

LFCP, realización de todos los tratamientos y seguimiento de la investigación, consolidación e interpretación de los datos. JCZ: planteamiento de la idea del trabajo, supervisión y participación en todo el proceso de ejecución

\section{Conflicto de intereses}

Los autores declaran que no existe conflicto de intereses que ponga en riesgo la validez de los resultados presentados.

\section{Financiación}

Esta investigación fue financiada por la Universidad de Caldas y realizada dentro de sus instalaciones.

\section{Referencias}

Agrios, G.N. (2005). Plant pathology. 5th Edition. Academic Press. New York, USA. p. 27, 422, 635, 831, 840-841, 867, 922.

Ángel-García, C., Robledo-Buriticá, J., Castaño-Zapata, J. (2018). Comparación de métodos de inoculación de Fusarium solani f. sp. passiflorae en plántulas de maracuyá (Passiflora edulis f. flavicarpa). Rev. U.D.C.A. Act. \& Div. Cient. 21 (1): 23-31.

Castaño-Zapata, J. (1994). Principios básicos de fitopatología. Zamorano Academic Press. Tegucigalpa, Honduras. 518 p.

Castaño-Zapata, J. (1998). Práctica de laboratorio de fitopatología. $2^{\text {a }}$ Edición. Universidad de Caldas-Zamorano Academic Press. 104p.

Castaño-Zapata, J. \& Salazar, H. (1998). Illustrated guide for identification of plant pathogens. Centro Editorial Universidad de Caldas. 108p.

Castaño-Zapata, J. (2002). Principios básicos de fitoepidemiología. Editorial Universidad de Caldas. 396p.

Cerkauskas, R. (2005). Fusarium wilt. Fecha de consulta: 14 de enero de 2019.- Disponible en: http://www.avrdc.org/pdf/ tomato/fusarium.pdf 
Estupiñán, H. \& Ossa, J. (2007). Efecto del agente causal de la marchitez vascular de la uchuva (Physalis peruviana L.), el hongo Fusarium oxysporum Schlecht, sobre algunas solanáceas y otras especies cultivadas afectadas por formas especiales del microorganismo. Tesis para optar al título de Ingeniero Agrícola y Veterinaria. Facultad de Ciencias. Pontificia Universidad Javeriana, Bogotá, Colombia. 89 p.

FAOSTAT. (2017). Statistical Databases. Food and Agriculture Organization of the United Nations. Roma. Italia. Fecha de consulta: 4 de marzo, 2019. Disponible en: http://www.fao. org/faostat/es/\#data/QC

Fischer, I., Lourenco, S., Martins, M., Kimati, H., Amorin, L. (2005). Seleção de plantas resistentes e de fungicidas para o controle da podridão do colo do maracujazeiro causada por Nectria haematococca. Fitopatología Brasileira. 30: 250-258.

Gordon, T.R. (2017). Fusarium oxysporum and the Fusarium wilt syndrome. Ann. Rev. Phytopathology. 55: 23-39.

Jaramillo, J., Rodríguez, V.P., Guzmán, M., Zapata, M., Rengifo, T. (2007). Manejo del cultivo de tomate. Manual Técnico Buenas Prácticas Agrícolas-BPA. La producción de tomate bajo condiciones protegidas. CORPOICA - MANA - Gobernación de Antioquia - Centro de Investigación "La Selva". FAO. 78: 133-134.

Jiménez, O., Contreras, N., Nass, H. (2004). Xanthomonas albilineans agente causal de la escaldadura foliar de la caña de azúcar (Saccharum sp.) en los estados Lara y Yaracuy. Rev. Fac. Agron. 21 (3): 233-245.

Jones, J.P. (1991). Fusarium wilt. p. 15-16. In: Compendium of Tomato Diseases. J. B. Jones, et al. (Editores). APS Press. The American Phytopathological Society. 73 p.

Kelman, A. (1967). Source book of laboratory exercises in plant pathology. APS. W. Freeman \& Company. U.S.A. 387 p.

Kranz, J. (1982). Enfermedades de los cultivos tropicales. Deuteromycotina. Primera edición. Paul Parey. Berlin \& Hamburgo. p. 213-214.

Leslie, J.F. and Summerell, B.A. (2006). Chapter 13. Fusarium oxysporum Schlechtendahl emend. Snyder \& Hansen. p. 212-218. The Fusarium Laboratory Manual. Blackwell Publishing, Hoboken.

López-Cardona, N. \& Castaño-Zapata, J. (2013). Etiología de la muerte descendente del tomate de árbol [Solanum betaceum (Cav.) Sendt.]. Revista Agronomía. 21 (1):7-18.

Lozovaya, V.V., Lygin, A.V., Hartman, G.L., Widholm, J.M. (2004). Biochemical response of soybean roots to Fusarium solani f.sp. glycines infection. Crop Science. 44 (3): 819-826.

Lugo, Z.C. \& Sanabria, N.H. (2001). Características culturales y patogénicas en aislamientos de Fusarium oxysporum $\mathrm{f}$. sp. lycopersici, procedentes de plantaciones comerciales de tomate. Agronomía Tropical. 51 (4): 519-530.

McGovern, R.J. \& Datnoff, L.E. (1992). Fusarium crown and root rot of tomato: Reevaluation of management strategies. En: Vavrina, C.S. (Editores), Fla. Tom. Instit. Proc., Vegetable Crops Special Series, SS HOS1 University of Florida-IFAS, p. $75-82$.
Morales, N., Espinosa, G., Morales, A., Sánchez, B., Jiménez, A., Milián-García, Y. (2014). Caracterización morfológica y evaluación de resistencia a Fusarium oxysporum en especies silvestres del género Solanum sección lycopersicon. Rev. Colomb. Biotecnol. 16 (1): 62-73.

Murashige, T. \& Skoog, F. (1962). A revised medium for rapid growth and bioassays with tobacco tissue cultures. Physiol. Plantarum. 15: 473-497.

Mycobank. (2017). Search on: Mycobank names. Utrecht, The Netherlands. MYCOBANK Data base Fungal Data bases. Nomenclature \& Species Banks. Fecha de consulta: 16 de abril, 2019. Disponible en: http://www.mycobank.org/ BioloMICSDetails.aspx?Rec $=203140$

Narayanasamy, P. (2011). Detection of fungal pathogens in plants. En: Fungal Pathogens. Springer \& Dordrecht (India). 200 p.

Nelson, P.E. (1981). Life cycle and epidemiology of Fusarium oxysporum. p: 51-80. En: M. E. Mace, A: A: Bell and C. C. H. Beckman. (Editores). Fungal Wilt Diseases of Plants. Academic Press. New York.

Okiror, M. A. (1998). Screening techniques for Fusarium wilt of pigeon pea. African Crop Science Journal. 6 (4): 345-350.

Ortíz, E. \& Hoyos, L. (2016). Standard methods for inoculations of $F$. oxysporum and F. solani in Passiflora. African J. Agricultural Res. (Nigeria). 11 (17):1569-1575.

Poulsen Hornum, M., Ridao, A. Del C. \& Castaño, F. (2013). Comparación entre técnicas de inoculación de Fusarium verticillioides en espigas de maíz. Revista de Investigaciones Agropecuarias (RIA). 39 (3): 312-317.

Ramyabharathi, S.A., Meena, B., Raguchander, T. (2012). Induction of chitinase and $\beta$-1, 3-glucanase PR proteins in tomato through h liquid formulated Bacillus subtilis EPCO 16 against Fusarium wilt. Journal of Today's Biological Sciences: Research \& Review. India. 1 (1): 50-60.

Rick, C. M. (1974). El tomate, Investigación y Ciencia. Scientific American No. 25 Edición. Reverté S. A. Barcelona, España Pp. 46.

SAS. (1992). En: SAS Institute Cary, N.C. EEUU. Version 9,0.

Singh, E. \& Dwivedi, S. K. (2014). Effectiveness of some antagonistic fungi and botanicals against Fusarium solani and Fusarium oxysporum f. sp. lycopersici infecting brinjal and tomato plants. Asian J. of Plant Pathology. 18 (1): 18-26.

Trandafirescu, M. \& Botu, M. (2009). Epidemiology of bacterial dieback of peach (Pseudomonas mors-prunorum f. sp. persicae) in the conditions of Valu lui Traian fruit growing area. Cetara (SA) Italy. p. 1-6. Fecha de consulta: 25 de junio, 2015. Disponible en: http://www.cost873.ch/ uploads/_files/MBotu_BacterialDiebackPeachRomania.pdf

Walker, J. C. (1971). Fusarium wilt of tomato. Monograph No. 6, Am. Phyt. Soc. St. Paul, Minn. p. 95-97.

Williams, P.H. (1981). Fusarium yellows. In: Screening Crucifers for Multiple Disease Resistance. University of Wisconsin, USA. p. 124-129. 